\title{
Consensus on items and quantities of clinical equipment required to deal with a mass casualties big bang incident: a national Delphi study
}

Edward A S Duncan ${ }^{1 *}$, Keith Colver ${ }^{2}$, Nadine Dougall ${ }^{3}$, Kevin Swingler ${ }^{4}$, John Stephenson ${ }^{5}$ and Purva Abhyankar ${ }^{1}$

\begin{abstract}
Background: Major short-notice or sudden impact incidents, which result in a large number of casualties, are rare events. However health services must be prepared to respond to such events appropriately. In the United Kingdom (UK), a mass casualties incident is when the normal response of several National Health Service organizations to a major incident, has to be supported with extraordinary measures. Having the right type and quantity of clinical equipment is essential, but planning for such emergencies is challenging. To date, the equipment stored for such events has been selected on the basis of local clinical judgment and has evolved without an explicit evidence-base. This has resulted in considerable variations in the types and quantities of clinical equipment being stored in different locations. This study aimed to develop an expert consensus opinion of the essential items and minimum quantities of clinical equipment that is required to treat 100 people at the scene of a big bang mass casualties event.
\end{abstract}

Methods: A three round modified Delphi study was conducted with 32 experts using a specifically developed web-based platform. Individuals were invited to participate if they had personal clinical experience of providing a pre-hospital emergency medical response to a mass casualties incident, or had responsibility in health emergency planning for mass casualties incidents and were in a position of authority within the sphere of emergency health planning. Each item's importance was measured on a 5-point Likert scale. The quantity of items required was measured numerically. Data were analyzed using nonparametric statistics.

Results: Experts achieved consensus on a total of 134 items (54\%) on completion of the study. Experts did not reach consensus on $114(46 \%)$ items. Median quantities and interquartile ranges of the items, and their recommended quantities were identified and are presented.

Conclusions: This study is the first to produce an expert consensus on the items and quantities of clinical equipment that are required to treat 100 people at the scene of a big bang mass casualties event. The findings can be used, both in the UK and internationally, to support decision makers in the planning of equipment for such incidents.

Keywords: Mass casualties, Major incident, Ambulance, Delphi method, Internet, Paramedic, Big bang, Clinical equipment

\footnotetext{
* Correspondence: edward.duncan@stir.ac.uk

${ }^{1}$ NMAHP Research Unit, Scion House, University of Stirling, Stirling, FK9 4LA,

Scotland, UK

Full list of author information is available at the end of the article
}

\section{Biomed Central}

(c) 2014 Duncan et al.; licensee BioMed Central Ltd. This is an Open Access article distributed under the terms of the Creative Commons Attribution License (http://creativecommons.org/licenses/by/2.0), which permits unrestricted use, distribution, and reproduction in any medium, provided the original work is properly credited. 


\section{Background}

Major short-notice or sudden impact (known as big bang [1]) incidents which result in a large number of casualties are, fortunately, rare events. However they do occur and health services must be prepared to respond appropriately. In the United Kingdom (UK), as with most developed countries, normal response ambulances will not have the capacity to carry the extra equipment which is required to care for these patients while at the incident [2].

In order to deal with a big bang mass casualties incident, National Health Service (NHS) organizations, including ambulance services must be supported by extraordinary measures [1]. As part of their role UK NHS ambulance services maintain and deploy extra clinical equipment for big bang mass casualties emergencies [2]; and, on arrival at such an incident, establish and manage a casualty clearing station. Individuals are then triaged and receive emergency medical treatment as required before transportation to hospital. However, the London Assembly Report into the 2005 London Bombings highlights the challenges of achieving this in practice: The London Ambulance Service lacked essential supplies, such as fluids triage cards and tourniquets, at all sites [3].

Predicting the types and quantities of clinical equipment that will be required at a mass casualties big bang event is difficult. It is necessary to consider the wide range of incidents [1], both natural and man-made, that could cause such an event, and the resultant broad spectrum of potential clinical need:- e.g. haemorrhage, burns, respiratory disorders; fractures; effects of smoke inhalation etc. The response must also be tailored to the level of care that can be practically delivered in a pre-hospital environment. A recent systematic review highlighted the lack of evidence to inform policymakers and service providers about the types and quantities of clinical equipment required at a mass casualties big bang event [4].

Current UK ambulance service provision of clinical equipment at big bang mass casualties incidents has developed on the basis of local clinical judgment over many years, without any central co-ordination or clear evidence-base. This has resulted in variations in stock type and quantity throughout the UK. Agreeing the types and quantities of clinical equipment required at a big bang mass casualties emergency would be advantageous. At a national level it would provide policy and strategic decision-makers with knowledge to support them in planning future service provision. More locally it may enable services to make more efficient use of their resources.

This study, therefore, aims to address the current lack of knowledge about appropriate clinical equipment for dealing with a mass casualties big bang [1] event. Specific research questions are: what are a) the most important items of clinical equipment required to treat 100 people at the scene of a big bang mass casualties event?; and b) the minimum quantities required of each item?

\section{Methods}

Participants were asked to consider what would be required to provide immediate patient care for 100 people in the pre-hospital phase of a big bang mass casualties incident. The study was based on current UK planning assumptions $[1,5]$ for such events (Table 1). The figure of 100 people was chosen, firstly as it was a conceptually straightforward number of casualties to conceptualize, and secondly as it would allow easy calculations of quantities of items required at mass casualty incidents, as the results of the study could be simply multiplied as required.

A modified Delphi study method was used. Originally developed by the RAND Corporation in the 1950's [6], the Delphi method has since been used extensively in healthcare research [7-11], including emergency care research [12-17], amongst other fields. Since its inception, many Delphi studies have varied slightly from the original RAND Corporation method, and it is therefore common to find studies described as 'modified Delphi studies', or using a Delphi approach [7]. Delphi studies use a form of consensus methodology to develop a reliable consensus of a group of experts on a specific topic. The Delphi method involves a series of questionnaires, or 'rounds' (typically 3), on a specific topic being completed by subject experts. These rounds are interspersed by controlled feedback which includes the participant's own judgment and the overall group judgment for comparison. Participants are then given the opportunity to revise their judgment in the following round if they so desire. Participants' individual responses are unknown to the group [18].

Given the variability of study methods that have been used and described as 'Delphi', it is important to outline the features that ensure the credibility of findings for this approach. These are: a clear description of why a Delphi method has been used; the choice of participants that form the expert panel; transparency of data collection procedures used; the choice of consensus level; and the means of dissemination [19]. A study reference group comprised of a small number of key leaders in the field was formed to support the study. Key tasks for the group were to: agree the study protocol; identify potential participants; provide expert comment on the study findings.

An opinion on the status of this study was sought from the NHS Lothian Ethics Committee who advised that for the purposes of ethical approval, the study was classifiable as a service evaluation [20]. The Scottish Ambulance Service Research Governance Committee, as 


\begin{tabular}{|c|c|c|}
\hline Category & Patient condition & $\%$ of total \\
\hline P1 & $\begin{array}{l}\text { Casualties needing immediate } \\
\text { life-saving resuscitation and/or surgery }\end{array}$ & $25 \%$ (25 casualties) \\
\hline P2 & $\begin{array}{l}\text { Stabilized casualties needing early } \\
\text { surgery but delay is acceptable }\end{array}$ & $25 \%$ (25 casualties) \\
\hline P3 & $\begin{array}{l}\text { Casualties requiring treatment } \\
\text { but a longer delay is acceptable }\end{array}$ & $50 \%$ (50 casualties) \\
\hline
\end{tabular}

the NHS Scotland Special Health Board for pre-hospital emergency care, granted Research and Development study approval. All data and participant information was stored securely in line with good research practice guidelines.

\section{Sample}

Participants were purposively selected according to the following criteria, which defined our 'expert participant':-

1. Individual clinical (paramedical or medical) experience of providing a professional pre-hospital emergency medical response to a mass casualties incident; or

2. Responsibility in health emergency planning for mass casualties' incidents and be in a position of authority and influence within the sphere of health emergency planning and response.

Potential participants were identified through the study reference group and researchers' knowledge base. The researchers used a snowballing method of recruitment to increase the potential participant base by asking the initial group to identify other potential participants who met the inclusion criteria. Letters of invitation to participate in the study were sent to 141 individuals. The majority of people invited to participate were located in the UK, but a few $(n=7)$ were based in other countries with similar emergency response strategies.

People interested in participating in the study were asked to email the study research paramedic (KC) to note their interest. They were then provided with a unique password, log-in, and link to the study website. The password and log-in linked the individual in each round of data collection, and enabled them to exit and re-enter the study website in order to complete each round as their time allowed.

\section{Data collection}

Data was collected using a purposively designed study website. This enabled the study to be carried out on-line via a web browser instead of relying on paper-based questionnaires. Although the website was developed specifically for this study, it was designed in a manner that would allow its use in further Delphi studies with minimal adaptation. Individuals could not register and take part in the study from the site alone - they needed the password and unique identifier that was sent to them by the research team. Inter-round data analysis was completed automatically and significantly reduced the administration that is normally required to be undertaken between rounds of a Delphi study. The web site included the usual features you would expect from such a service. Having logged in, the user was presented with the Delphi questionnaire and, if they had already started it, the values they had entered. Participants were prompted to save their responses as they progressed through the study and whenever they logged out of the website. This allowed the participant to return to the site and complete the questionnaire in more than one sitting. Electronic reminders were sent automatically two weeks after the commencement of each round, and also in the final stages to those individuals who had not yet completed the round. These reminders stated the final date by which the current round must be completed. An a priori decision was made to limit the study to three rounds of data collection to minimize participant fatigue [21]. The website was piloted for acceptability and usability by Scottish Ambulance Service Special Operations Response Team ambulance clinicians and emergency planning officers. Feedback from the pilot stage was positive, although individuals noted that the task was substantial due to the number of items included.

\section{Round one}

Items for round one $(\mathrm{n}=232)$ were collated from the researchers' existing knowledge of current stock for mass casualties incidents in the UK. The list of items to rate was long, so they were split into subsets according to their purpose (i.e. Items relating to Airway; Breathing; Circulation; Examination Medicines; Splintage; Comfort; Control of Infection; Transport; Other) each with a separate tab on the web-page. This made the questionnaire look less daunting and helped users find the item they had reached if they had saved their partial progress, and returned later.

Participants were asked to carry out two tasks for each listed item. Firstly, they were asked to rate the importance they would give to each item along a scale of 1 to 5 (Very unimportant -1 ; Quite unimportant -2 ; Neither -3 ; Quite important - 4; Very important - 5); and secondly, they were asked to state how much of each item they believed would be required to treat 100 patients at the scene of a big bang mass casualties incident. Participants were offered the chance to click a button to declare that they had no opinion or knowledge for any given item. This also allowed an automatic check via the web site that no items had been accidently missed. The web site displayed a bar to inform the user of their progress and offered a facility to help them find any items they had missed. Participants 
who had completed less than $100 \%$ of the questionnaire were automatically emailed a reminder before the end of each round. Participants were also able to add any clinical items (for inclusion in round two) which they felt were important but missing from the round one list.

\section{Round two}

Participants were asked to review the aggregated findings for the previous round together with their previous individual ratings, as well as 16 unique items of clinical equipment added in round one. Participants were invited to reconsider their rating of importance and quantification for each item. As in the previous round, electronic reminders were sent out to all non-completing participants after two weeks.

\section{Round three}

Participants were again asked to review the aggregated findings for the previous round together with their previous individual ratings, and were again invited to reconsider their rating and quantification for each item of equipment in respect of the results of round two. Electronic reminders were sent out after two weeks.

\section{Data handling}

Delphi studies vary considerably in how they handle and analyze their data [18]. The computerization of the study allowed the data to be presented to participants in a novel and more meaningful way. Data from rounds two and three were presented to participants as a color histogram (or heat map) where the depth of color indicated the frequency with which respondents in the previous round had chosen each rating. Figure 1 shows the frequency with which each of the five responses had been chosen in the previous round (dark being many, light being few). The grey circle shows the choice that the current participant made on the previous round and the green circle shows the choice that they have made on the current round, (in round one each box was white as no previous selection had been made). In this way, participants could easily see how their responses compared to the consensus in the previous round and either confirm or update their response accordingly.

The second question required a numeric answer. As the user sample size in each round exceeded 30 (and therefore the number of independent responses was sufficient to assume that the central limit theorem held with responses tending towards being normally distributed), we proceeded to adopt a parametric approach in the iterative feedback to users between rounds. Feedback to the user was given as a color again, but in this case, the depth of color indicated the number of standard deviations between the user's response and the mean response (in other words, the z-score). As the scale for each answer was different, the normalized $\mathrm{z}$-score provided a consistent measure of agreement for each question. Z-scores were calculated as,

$$
z=\frac{x-\mu}{\sigma}
$$

Where $x$ was the value for which the $\mathrm{z}$-score is to be calculated, $\mu$ was the mean of the values of the previous round and $\sigma$ was the standard deviation of the values from the previous round. The $\mathrm{z}$-score was translated into a color depth and shown around the input box for each item in the questionnaire. The mean value from the previous round, along with the participant's own response from the previous round were also displayed on the questionnaire. An example of the quantity input box is given in Figure 2; the top box shows that the previous average quantity for this item was 73 and that this participant had said 53. The light color indicates the difference. The bottom box shows where the participant was in closer agreement in the last round. The numbers in the boxes show the participant's updated response for this round.

\section{Consensus}

As the focus of this study was to understand which items should be included in a mass casualties response, it was important to understand which items gained consensus as being 'important' or 'very important', and conversely, which items were viewed as being 'unimportant', or 'very unimportant'. An item was deemed to be 'important' or 'very important' if it had been rated as either four or five by at least $80 \%$ of respondents. Similarly, an item was deemed to be 'unimportant' or 'very unimportant' if it had been rated as either two or one by at least $80 \%$ of respondents.

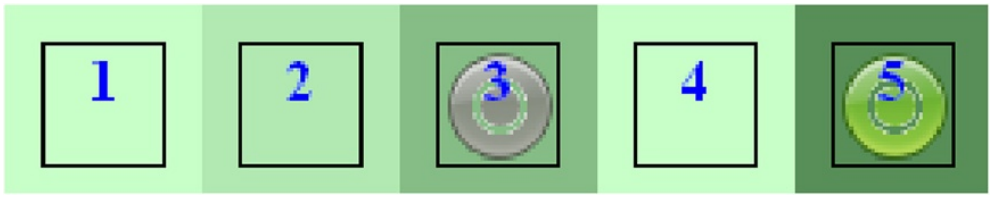

Figure 1 An example from the website of a color histogram of previous responses. 


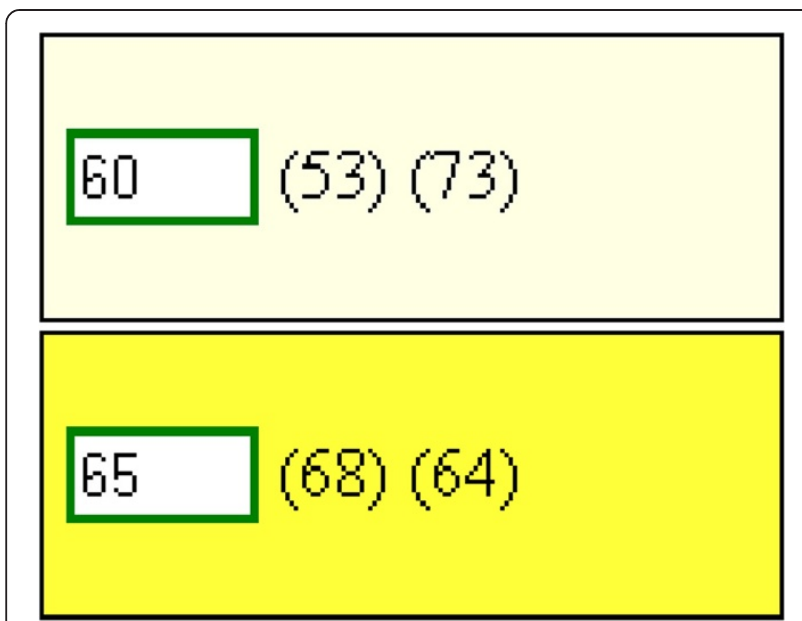

Figure $\mathbf{2}$ The quantity input box for two items as presented on the website.

\section{Analysis plan}

Frequently in Delphi studies the mean value and standard deviation of ratings are presented. However, these are likely to be sub-optimal measures as it is more likely that the responses will form a skewed distribution. For example, if half the respondents in our study chose a score of 1 , and half chose 5 , then reporting a mean of 3 would fail to illustrate that the data had a bi-modal distribution. Therefore we proposed use of non-parametric approaches in the data analyses.

Research Question 1: A descriptive analysis of the total number of items that reached consensus of being important (agreement by at least $80 \%$ of participants) would be summarized. A statistical test of significant difference in consensus of item importance between rounds would be tested by Wilcoxon Rank Sum Test for independent events - if the 20 additional items added to the list between rounds one and two achieved consensus; otherwise the Wilcoxon Signed Rank Test for matched pairs was proposed.

Research Question 2: A descriptive analysis of the recommended median quantities of items that reached consensus (agreement by at least $80 \%$ of participants) would be summarized. A statistical test of significant difference in consensus of median items required between rounds will be tested by a Wilcoxon Signed Ranks Test for independent events.

\section{Results}

Sixty individuals responded to the letter of invitation stating that they wished to participate. Forty-five participants (75\%) completed round one of the study. Thirty-five participants (58\%) completed round two, and 32 participants $(53 \%)$ completed round three; 16 were ambulance clinicians, and 16 were medical personnel.

\section{Item consensus}

A total of 16 new items were added following round one. Raters gained consensus on one hundred and thirty four items $(54 \%)$ by round three. This figure increased to 164 items (66\%) if the items which the raters neared consensus on (those $>=70 \%$ ) are considered. Almost all the items which reached consensus were viewed as 'important' or 'very important' by participants; only four items on which raters reached consensus on were viewed as 'unimportant' or 'very unimportant' (i.e. rectal thermometer; Clopidogrel (300 mg); Clindamycin; Saline ampule (5 mls)); a further two items 'nearing' consensus, that is reaching $70-79 \%$ agreement, were also rated as 'unimportant' or 'very unimportant' (i.e. OPA (Size 000); ET Tube size 10).

There was considerable variation in the percentage of items that gained consensus within the subsets that had been split according to each item's purpose. Subsets with the highest percentage of items reaching consensus were 'Control of Infection' (100\%; $\mathrm{n}=10)$; 'Splintage' (73\%; $\mathrm{n}=8$ ); and 'Circulation' (73\%; $\mathrm{n}=35)$. Subsets that had the fewest items that reached consensus were 'Medicine2' $(31 \% ; n=5)$; and 'Airways2' (35\%; $n=11)$. Consensus for each of these subsets increased when items 'nearing' consensus (i.e. $>70 \%$ ) were also considered, (see Table 2). Items that gained consensus amongst raters as being important or very important are listed in Table 3. A full list of items and levels of consensus reached is also provided, (see Additional file 1).

Round one contained 232 items and rounds two and three contained an additional 16 items, bringing the total number of items to 248 for the last two rounds. The median Likert scores observed for 232 items in each of rounds one, two and three were 4, 5 and 5, respectively,

Table 2 Consensus levels of items' importance

\begin{tabular}{lcccc}
\hline Group & $\begin{array}{c}\text { Number of } \\
\text { items in group }\end{array}$ & \multicolumn{3}{c}{$\begin{array}{c}\text { Agreement of number of items } \\
\text { at end of round } \mathbf{3}(\%)\end{array}$} \\
\cline { 3 - 5 } & & $\mathbf{2 8 0 \%}$ & $\mathbf{2 7 0 \%}$ & $\leq \mathbf{6 9 \%}$ \\
\hline Airway 1 & 17 & $10(59)$ & $12(71)$ & $5(29)$ \\
Airway 2 & 31 & $11(35)$ & $15(48)$ & $16(52)$ \\
Breathing & 16 & $10(62)$ & $10(62)$ & $6(38)$ \\
Circulation & 48 & $35(73)$ & $44(92)$ & $4(8)$ \\
Examination & 18 & $9(50)$ & $9(50)$ & $9(50)$ \\
Medicine 1 & 50 & $21(42)$ & $31(62)$ & $19(38)$ \\
Medicine 2 & 16 & $5(31)$ & $7(44)$ & $9(56)$ \\
Splintage & 11 & $8(73)$ & $10(91)$ & $1(9)$ \\
Comfort & 6 & $3(50)$ & $3(50)$ & $3(50)$ \\
COI & 10 & $10(100)$ & $10(100)$ & $0(0)$ \\
Other & 14 & $6(43)$ & $6(43)$ & $8(57)$ \\
Transport & 11 & $6(43)$ & $7(64)$ & $4(36)$ \\
Totals & $\mathbf{2 4 8}$ & $\mathbf{1 3 4}(54)$ & $\mathbf{1 6 4}(\mathbf{6 6})$ & $\mathbf{8 4}(\mathbf{3 4})$ \\
\hline
\end{tabular}


Table 3 Items that gained consensus as 'Important' and 'Very Important' and their recommended quantities Subset \& item (shaded items neared consensus) Quantity Median (IQR)

\begin{tabular}{lc}
\hline \multicolumn{1}{c}{ Airway 1 } \\
\hline OPA size 3 & $25(20-25)$ \\
OPA size 4 & $25(20-25)$ \\
Suction catheter - hard & $30(25-35)$ \\
Nasopharyngeal airway 7 & $22(2-25)$ \\
Suction - handheld manual & $23(20-25)$ \\
Non-inflatable SG Airway device & $21(20-25)$ \\
Nasopharyngeal airway 6 & $22(20-25)$ \\
OPA size 2 & $15(10-15)$ \\
Particulate respirators [dust mask] & $75(50-100)$ \\
Suction - battery powered & $10(8-10)$ \\
\hline
\end{tabular}

ET Securing device

Catheter mount

Laryngeal mask size 2

$25(20-25)$

$25(25-25)$

$10(5-10)$

Laryngeal mask size 4

$16(15-20)$

Laryngoscope \& Blade(s) - adult

$20(15-20)$

Magill forceps - adult

$20(15-20)$

ET Tube size 8

$15(10-15)$

Surgical airway set

ET Tube size 7

$8(5-10)$

$15(10-15)$

Laryngeal mask size 5

$15(10-15)$

Laryngoscope \& Blade(s) - child

Breathing

Bag Valve mask - adult

$10(6-10)$

Bag Valve mask - child

Chest seal

Reservoir mask and tubing - adult

Reservoir mask and tubing - child

Nebuliser mask and tubing - adult

Nebuliser mask and tubing - child

Portable ventilator

$25(20-25)$

$10(10-13)$

25 (25-30)

50 (40-50)

$25(25-30)$

$25(24-30)$

20 (15-20)

$10(10-15)$

Chest/thoracic drainage kits and sets

$15(10-15)$

Bag valve mask - infant

$10(5-10)$

\begin{tabular}{lc}
\hline \multicolumn{2}{c}{ Circulation } \\
\hline 3 way tap \& extension tube (IO/IV) & $35(30-40)$ \\
Blast bandage & $80(75-100)$ \\
Disposable latex free tourniquet IV access & $50(50-50)$ \\
EZ IO & $10(10-10)$ \\
Haemostatic dressings & $80(70-100)$ \\
Administration set blood and blood derivatives & $55(50-60)$ \\
Combat application tourniquet & $60(50-70)$ \\
Syringe 2 ml & $50(46-50)$
\end{tabular}

Table 3 Items that gained consensus as 'Important' and 'Very Important' and their recommended quantities (Continued)

Transpore/micropore tape

$55(50-60)$

Cannula $16 \mathrm{~g}$

50 (50-50)

Cannula $18 \mathrm{~g}$

$50(50-51)$

IO Catheter

30 (25-36)

IO needle blue

15 (14-20)

IO needle red

$15(10-20)$

IO needle yellow

$15(12-20)$

Cannula $20 \mathrm{~g}$

50 (40-50)

Dressing - extra large

$90(75-100)$

Dressing - large

100 (100-100)

Dressing - medium

100 (100-110)

Dressing wound with conforming stretch bandage

$85(80-100)$

100 (100-125)

60 (50-95)

$95(76-100)$

$29(20-30)$

$50(50-50)$

50 (50-60)

$62.5(50-75)$

$6(5-10)$

$100(93-100)$

30 (25-40)

50 (50-50)

20 (15-25)

$100(80-100)$

$12(10-15)$

AED Pads - adult

$7(5-10)$

AED Pads - child

20 (15-20)

Stethoscope - adult

Examination

Monitor SPO2

25 (22-30)

Glucose test strips (for use with glucose meter)

60 (50-75)

Triage tape - child

10 (10-14)

Glucose meter

10 (10-10)

Rectal thermometer

$5(0-5)$

Monitor $\mathrm{CO} 2$

15 (10-20)

Torch - examination pen disposable 25 (25-25)

Manual sphygmomanometer 15 (10-15)

\begin{tabular}{ll}
\hline \multicolumn{2}{c}{ Medicines1 } \\
\hline Morphine sulphate
\end{tabular}

Oxygen mass delivery [1 unit] $3(2-4)$

Saline .9\% $500 \mathrm{mls}$ bag

$90(75-100)$

Naloxone hydrochloride (Min-l-jet, $2 \mathrm{mg} / 5 \mathrm{mls}$ )

$35(25-50)$

Salbutamol - Nebuliser liquid 2 mg/ml $2.5 \mathrm{ml}$ UDV

$45(40-50)$ 
Table 3 Items that gained consensus as 'Important' and 'Very Important' and their recommended quantities (Continued)

\begin{tabular}{|c|c|}
\hline Clopidogrel 75 mg & $2.5(0-5)$ \\
\hline Oxygen D size & $28(25-30)$ \\
\hline Entonox [with mouthpiece] & $25(20-25)$ \\
\hline Adrenaline (1 mg/1 ml, 1:1000) & $20(20-25)$ \\
\hline Adrenaline (Min-l-Jet, 1 mg in 10 ml, 1:10,000) & $40(30-50)$ \\
\hline Lidocaine $-100 \mathrm{mg} / 10 \mathrm{ml}(1 \%)$ solution for injection pfs & $20(15-25)$ \\
\hline Saline ampoule $10 \mathrm{mls}$ & $100(82-100)$ \\
\hline Clopidogrel $300 \mathrm{mg}$ & $5(0-5)$ \\
\hline Ipratopium bromide $(6 \times 250$ mcg/1 ml) & $20(15-20)$ \\
\hline Clindamycin & $5(0-5)$ \\
\hline Atropine sulphate (Min-l-Jet, 3 mg in $10 \mathrm{ml}$ ) & $28(25-31)$ \\
\hline Diazepam emulsion $10 \mathrm{mg}$ in $2 \mathrm{mls}$ & $22(20-25)$ \\
\hline Eyewash $500 \mathrm{mls}$ & $30(25-40)$ \\
\hline Saline $10 \mathrm{mls}$ pre-filled syringe & $50(50-52)$ \\
\hline Saline ampule $5 \mathrm{mls}$ & $15(0-20)$ \\
\hline Oxygen F size & $10(10-12)$ \\
\hline \multicolumn{2}{|l|}{ Medicines2 } \\
\hline Tranexamic acid & $50(40-50)$ \\
\hline Ketamine & $47.5(40-50)$ \\
\hline Midazolam & $45(35-50)$ \\
\hline Suxamethonium chloride -Injection PFS 100 MG/2 ML & $21(20-25)$ \\
\hline Ondansetron 4 mg & $20(19-25)$ \\
\hline \multicolumn{2}{|l|}{ Splintage } \\
\hline Pelvic sling & $25(25-30)$ \\
\hline Cervical collars (set) & $25(20-30)$ \\
\hline Head hugger with straps & $25(20-25)$ \\
\hline Frac straps/packs & $20(16-25)$ \\
\hline Traction splint & $20(16-20)$ \\
\hline Triangular bandage & $50(50-50)$ \\
\hline Box splint & $25(20-25)$ \\
\hline Tape $100 \%$ cotton for medical or general use & $25(20-30)$ \\
\hline \multicolumn{2}{|l|}{ Comfort } \\
\hline Emergency blanket & $120(100-127)$ \\
\hline Re-robe/modesty suits & $65(50-75)$ \\
\hline De-robe suits & $65(50-75)$ \\
\hline \multicolumn{2}{|l|}{ Control of infection } \\
\hline Clinical waste bag & $100(100-120)$ \\
\hline Latex free gloves extra large & $102(100-147)$ \\
\hline Latex free gloves large & $150(107-195)$ \\
\hline Latex free gloves medium & 150 (139-195) \\
\hline Latex free gloves small & $115(100-145)$ \\
\hline Alcohol hand gel & $50(40-60)$ \\
\hline Sharps box . $2 \mathrm{lt}$ & $20(14-20)$ \\
\hline Sharps box $10 \mathrm{lt}$ & $10(5-12)$ \\
\hline
\end{tabular}

Table 3 Items that gained consensus as 'Important' and 'Very Important' and their recommended quantities (Continued)

\begin{tabular}{lc}
\hline $\begin{array}{l}\text { Skin wipes (Tub) } \\
\text { Pre injection swabs }\end{array}$ & $30(16-34)$ \\
\hline \multicolumn{1}{c}{ Other } & $150(112-200)$ \\
\hline Entonox mouthpiece & $50(40-50)$ \\
$\begin{array}{l}\text { Tuffcut scissors } \\
\text { Self help packs }\end{array}$ & $30(25-30)$ \\
Medication/drug syringe stickers & $75(64-94)$ \\
Shears - hardened stainless steel, circa 25 cm & $120(100-150)$ \\
Scalpel & $20(20-25)$ \\
\hline & $25(20-25)$ \\
\hline Carry sheet & Transport \\
Rescue board and straps & $30(25-39)$ \\
Stretcher - drag & $15(10-20)$ \\
Stretcher - orthopaedic & $15(10-15)$ \\
Stretcher - large wheeled & $11(10-15)$ \\
Stretcher - basket & $10(4-10)$ \\
\hline
\end{tabular}

(all with IQR 3 to 5). The non-parametric test for independent events failed to compute, most of the responses were tied in pairs, therefore the Wilcoxon Signed Ranks Test was used to assess whether there was a significant increase in consensus between rounds. A significant difference was found between median Likert scores for the 232 matched pairs of items between round one and round three $(\mathrm{Z}=-5.26 ; 151$ ties; $\mathrm{p}<0.001)$; but not between round two and round three $(\mathrm{Z}=-1.79 ; 215$ ties; $\mathrm{p}=0.074)$.

\section{Quantity of items required}

The median quantities, and Inter Quartile Ranges (IQR), of items that gained consensus by raters are listed in Table 3. Whether the recommended quantities of items between rounds was a statistically significant improvement in participants' consensus was tested using a Wilcoxon Signed Ranks Test. A significant difference was found between the median number of items for the 232 matched pairs of items between round one and round three $(\mathrm{Z}=-9.83$; ties $=80 ; \mathrm{p}<0.001)$; and also between round two and round three $(\mathrm{Z}=-2.39$; ties $=160 ; \mathrm{p}=0.017)$. Whilst participants suggested similar quantities for many items by round three, other items still had considerably wider recommended quantities. This is clearly evident in the persistently large IQR of some items (e.g. Large Latex Free gloves had a median recommend quantity of 150, but an interquartile range of 107-195).

\section{Discussion}

Providing appropriate quantities of the right clinical equipment to the scene of a mass casualties big bang 
event is vital. But planning for such emergencies is challenging. This study has, for the first time, produced an expert consensus on the items and quantities of clinical equipment that are required to treat 100 people at the scene of a big bang mass casualties event. The results of this study clearly identify the equipment that is deemed of greatest importance. Items of clinical equipment that are highly likely to be required in the immediate care and treatment of trauma patients (e.g. morphine, oxygen, stretchers and carry sheets) were rated of greater importance than other items which may not be as essential (e.g. Hydrocortisone, Aspirin, Maternity pack, or Pillows).

The study used a specifically developed website for data collection. This enabled data to be presented to participants visually, overcoming some of the known limitations of using measures of central tendency $[7,18,21,22]$ when feeding back results to participants between rounds. The web-based platform also reduced the length of time required to conduct the study: analysis of each round's findings occurred automatically at a time appointed by the researchers and participants were immediately able to commence a further round of data collection. As data was stored electronically, the likelihood of human inputting error was also low and preliminary data analysis occurred automatically. However use of a web-based platform did not increase rates of study participation. Given its advantages, the researchers are now exploring the potential use of the web-based platform in future Delphi studies.

Consensus is reached in a Delphi study when a preagreed percentage of participants have rated items similarly. Ironically, there is little agreement within the Delphi study literature as to what constitutes a 'correct' percentage level of consensus. Previous Delphi studies show marked variation (between 50\% - 100\%) in consensus levels [18,23]. A consensus level of $80 \%$ was selected in this study as it marked a clear majority opinion and has been used in previous emergency medicine research using the Delphi method [14]. However, in recognition that the $80 \%$ cut-off selected was a strict and somewhat arbitrary definition of consensus, the items that gained at least $70 \%$ were highlighted in the study findings as items that were nearing the pre-set cut off. Ultimately the decision as to what is a sufficient degree of consensus is taken by those who use the study findings within their specific context, and not by the research team themselves.

In mass casualty big bang scenarios emergency equipment is transported to the scene as quickly as possible. The logistics of achieving this are considerable and space and resources are limited. This study provides policy makers and planners with information to support them in making an informed decision about the type and quantity of equipment that is immediately required at the scene to supplement the equipment, consumables and drugs that will already be on the ambulance vehicles attending the incident. The study results will help to minimize wastage from unnecessary equipment ordering, and to increase efficiency in routine equipment audits. The study findings were presented, at a UK wide implementation meeting, to a stakeholder group that comprised senior ambulance service clincians and managers, consultant emergency physicians, representatives from NHS England, NHS Wales and NHS Scotland, as well as English and Scottish Government policymakers and advisers. Structured discussions took place regarding the study findings. Services within NHS Scotland have since agreed to reconfigure their service and adopt the items that reached consensus, and their quantities, as the basis for stockpiling clinical equipment for mass casualties big bang incidents. In England and Wales, the output from the study and the implementation meeting have been presented to the NHS England Clinical Reference Group for Emergency Preparedness and are being used to redesign the contents of the English mass casualty vehicles.

\section{Limitations}

Delphi studies are onerous tasks, both in terms of activity required and the duration of involvement. Consequently participant attrition is a known limitation, but often hard to accurately calculate as the numbers of people invited to participate are rarely reported. In this study only $32(23 \%)$ of people invited to participate agreed and completed data collection over the three rounds. The study required participants to complete two tasks, a rating of an item's importance, and a quantification of how many of each item was required, instead of one. The former task is one for which Delphi method is well suited and traditionally employed; the latter arguably less so. This dual task and the sheer number of items to be rated $(n=248)$ may have contributed to participant attrition during the study. Whilst this is disappointing, the actual numbers of participants who completed all three rounds $(n=32)$ is similar to other Delphi pre-hospital emergency care research $[14,16]$. Researchers undertaking future Delphi studies in pre-hospital emergency care should aim to keep the number of items as manageable as possible, and estimate that they will need to invite approximately five times more individuals than the number they wish to participate. Attaching two rating tasks per item, whilst feasible, is undesirable due to the potential negative effect this may have on participant retention.

Only $54 \%$ of items reached consensus by the end of the study. This figure may have improved had further rounds of data collection occurred, but as the consensus between rounds two and three was not statistically significantly different, it is not very likely. In any case, the potential benefits of further data collection had to be 
balanced against the potential of participant fatigue and the potential of decreasing response rates [21]. Delphi studies accept participant responses at face value. As elsewhere [17] this study would benefit from further qualitative investigation to understand participants' responses in greater depth.

Whilst the median quantities of items are a useful starting point for services planning their resources, these need to be considered together with the local context that the service is working in: urban settings may have a higher frequency of standard emergency ambulances with a base loading of equipment, whereas more rural environments will have different considerations and require to factor in the longer distances that patients will be travelling to hospital following treatment on scene. Variation in the number of items required may have resulted from some participants misunderstanding the instructions, and consequently listing how many of an item they would wish to bring to an incident, rather than the number of items that they felt would actually be required on-scene.

\section{Conclusion}

An expert panel of individuals with either clinical experience of providing a professional pre-hospital emergency medical response to a mass casualties incident or responsibility and authority in health emergency planning for mass casualties incidents reached a consensus that 134 items of emergency clinical equipment were either important or very important when responding to a big bang mass casualties event. A further 30 items neared the agreed $80 \%$ consensus level. Indicative quantities for each item were provided. The study findings provide an important resource for the UK, and other countries with similar response mechanisms and planning assumptions, to inform the development of evidence-based policies and the planning of future emergency responses to big bang mass casualties events.

\section{Additional file}

Additional file 1: Levels of consensus on all items and recommended quantities.

\section{Competing interests}

The authors declare that they do not have any financial or non-financial competing interests in relation to this paper.

\section{Authors' contributions}

EASD led the study design, managed the overall study, chaired the study advisory committee, and drafted and revised the manuscript; KC was the study research fellow, he conceived the study idea, undertook day-to-day study management, participated in the study advisory committee and contributed to revisions of the final paper; ND provided statistical advice and expertise, and commented on revisions to the final paper; KS designed and managed the study website and background database, and commented on revisions to the final paper provided read and approved of the final manuscript; JS provided expert policy awareness, convened the study advisory committee, and commented on revisions to the final paper; PA advised on study design and statistical analysis, participated in the study advisory committee and contributed to revisions of the final paper. All authors read and approved the final manuscript.

\section{Acknowledgements}

A study advisory committee was set up to guide the researchers with expert subject area advice. Grateful thanks are given to the following individuals who participated in at least one meeting: Prof. Kevin Mackway-Jones (University of Manchester); Mr Mike Herriot (Scottish Ambulance Service); Dr Darren Walter (University of Manchester); and Mr David Whitmore (London Ambulance Service NHS Trust).

\section{Author details}

${ }^{1}$ NMAHP Research Unit, Scion House, University of Stirling, Stirling, FK9 4LA, Scotland, UK. ${ }^{2}$ Scottish Ambulance Service, Edinburgh, Scotland, UK. ${ }^{3}$ School of Nursing Midwifery and Health, The University of Stirling, Stirling, Scotland, UK. ${ }^{4}$ Department of Maths and Computing Science, University of Stirling, Stirling FK9 4LA, Scotland, UK. ${ }^{5}$ National Ambulance Resilience Unit, Unit 9 Granada Trading Estate, Demuth Way, Oldbury B69 4LH, UK.

Received: 18 July 2013 Accepted: 18 February 2014

Published: 22 February 2014

\section{References}

1. NHS Scotland Resilience Team at Scottish Government: Mass Casualties Incidents A Framework for Planning NHS Scotland. Edinburgh: Scottish Government; 2009

2. Government UK: Civil Contingencies Act. London: Stationary Office; 2004.

3. UK Government: Coroner's Inquests into the London Bombings of 7 July 2005. Report Under Rule 43 of The Coroner's Rules 1984. London: Stationary Office; 2012.

4. Timble J, Ringel J, Fox S, Pillemer F, Waxman D, Moore M, Hansen C, Knebel A, Ricciardi R, Kellermann A: Systematic review of strategies to manage and allocate scarce resources during mass casualty events. Ann Emerg Med 2013, 61:677-689.

5. Department of Health: Emergency preparedness division. Mass casualties incidents - A framework for planning. London: Stationary Office; 2007.

6. Linstone HA, Turoff M: The delphi method: techniques and applications. Technometrics 2002, 18:363.

7. Mead D, Mosely L: The use of delphi as a research approach. Nurse Researcher 2001, 8:4-37.

8. Duncan EAS, Nicol MM, Ager A: Factors that constitute a good cognitive behavioural treatment manual: a delphi study. Behav Cogn Psychother 2004, 32:199-213.

9. Dwyer M: A delphi survey of research priorities and identified areas for collaborative research in health sector library and information services UK. Health Libr Rev 1999, 16:174-91.

10. Aron $D$, Pogach $L$ : Quality indicators for diabetes mellitus in the ambulatory setting: using the delphi method to inform performance measurement development. Quality and Safety in Health Care 2008, 17:315-31.

11. Ager A, Stark L, Akesson B, Boothby N: Defining best practice in care and protection of children in crisis-affected settings: a Delphi study. Child Dev 2010, 81:1271-86.

12. Woollard M: Emergency calls not requiring an urgent ambulance response: expert consensus. Prehosp Emerg Care 2003, 7:384-91.

13. Crawford AWF, Mackway-Jones K, Russell D, Carley S: Planning for chemical incidents by implementing a Delphi based consensus study. Emerg Med J 2004, 21:24-29.

14. Carley S, Mackway-Jones K, Donnan S: Delphi study into planning for care of children in major incidents. Arch Dis Child 1999, 80:406-409.

15. Beattie $E$, Mackway-Jones $K$ : A Delphi study to identify performance indicators for emergency medicine. Emerg Med J 2004, 21:47-50.

16. Jensen J, Croskerry P, Travers A: Paramedic clincial decision making during high acuity emergency calls: design and methodology of a delphi study. BMC Emerg Med 2009, 9:17.

17. Jensen J, Croskerry P, Travers A: Consensus on paramedic clinical decisions during high-acuity emergency calls: results of a canadian delphi study. Can J Emerg Med 2011, 13:310-318. 
18. Powell C: The delphi technique: myths and realities. J Adv Nurs 2003, 41:376-82.

19. Fink A, Kosecoff J, Chassin M, Brook R: Consensus methods: characteristics and guidelines for Use. Santa Monica: RAND Corporation; 1991.

20. National Patient Safety Agency: Defining Research: NRES Guidance to help you decide if your project requires review by a Research Ethics Committee. 2010.

21. Williams $P$, Webb C: The delphi technique: a methodological discussion. J Adv Nurs 1994, 19:180-186.

22. Okoli C, Pawlowski SD: The Delphi method as a research tool: an example, design considerations and applications. Inf Manage 2004, 42:15-29.

23. Murphy M, Black N, Lamping D, McKee C, Sanderson C, Askham J, Marteau $\mathrm{T}$ : Consensus development methods, and their use in clinical guideline development. Health Technol Assess 1998, 2:3.

doi:10.1186/1471-227X-14-5

Cite this article as: Duncan et al:: Consensus on items and quantities of clinical equipment required to deal with a mass casualties big bang incident: a national Delphi study. BMC Emergency Medicine 2014 14:5.

\section{Submit your next manuscript to BioMed Central and take full advantage of:}

- Convenient online submission

- Thorough peer review

- No space constraints or color figure charges

- Immediate publication on acceptance

- Inclusion in PubMed, CAS, Scopus and Google Scholar

- Research which is freely available for redistribution 